\title{
Biologic monotherapy in the treatment of rheumatoid arthritis
}

This article was published in the following Dove Press journal:

Biologics:Targets and Therapy

14 May 2015

Number of times this article has been viewed

\section{Jacqueline Detert \\ Pascal Klaus}

Department of Rheumatology and Clinical Immunology, Charité Universitätsmedizin Berlin, Berlin, Germany

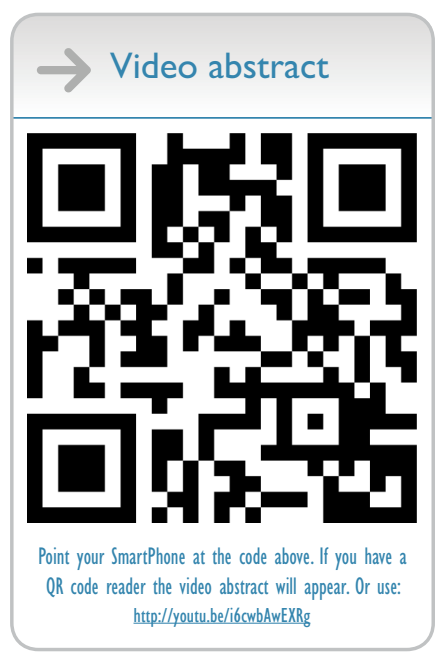

Correspondence: Jacqueline Detert Department of Rheumatology and Clinical Immunology, Charité -

Universitätsmedizin Berlin, Charitéplatz I, Berlin 10117, Germany

$\mathrm{Tel}+49304505$ I 3 I 33

Fax +49 $304505 \quad 13982$

Email jacqueline.detert@charite.de
Abstract: Biologics, possibly in combination with a conventional disease-modifying antirheumatic drug (DMARD) - preferably methotrexate (MTX), are used in accordance with the recommendations of the international rheumatological societies. However, in clinical practice, this recommendation is often problematic, as many rheumatologists know from personal experience. The quality of life of the patient is affected mainly by drug-induced intolerances (eg, MTX). Thus, the acceptance of the patient to treatment is often so inadequate that a discontinuation of the drug is necessary. In daily practice, approximately $30 \%$ of patients with biological therapy receive no concomitant DMARD according to the register data.

Keywords: efficacy, safety, methotrexate, autoimmune disease

\section{Introduction}

Rheumatoid arthritis (RA), an autoimmune disorder, is a chronic arthritis that affects five or more joints, and $0.5 \%-1.0 \%$ of adults worldwide suffer from this disease. ${ }^{1,2}$ It is characterized by persistent synovitis, systemic inflammation, and development of autoantibodies (particularly to rheumatoid factor and citrullinated peptide), ${ }^{3,4}$ The goal of treatment in RA management is to achieve a remission or a very low disease activity. As a first step, the patient is treated with a conventional synthetic diseasemodifying antirheumatic drug (csDMARD) therapy with or without concomitant glucocorticoid therapy recommended in order to achieve this goal., ${ }^{5,6}$ The key to success is the early initiation of therapy within the "windows of opportunity" with regular assessment of disease activity, and if necessary, adaptation of therapy in co-decision with the patient..$^{5-7}$

Methotrexate (MTX) remains the standard therapy for RA, but despite the introduction of other csDMARDs, the remission rate for MTX treatment is $<65 \% .{ }^{8}$ Biologics affect pro-inflammatory factors (cytokines, cytokine receptors, and specific inflammatory cell types). High-cost biological treatments (biological DMARDs, bDMARDs) are usually reserved for use if csDMARDs are ineffective and contraindicated, and in cases of nonresponse, drug-induced adverse events (AEs), or bad compliance of patient (Figure 1)..$^{5-7,9}$

Evidence for biological monotherapy, obtained as a result of clinical trials, are often only available as an accompanying statement. ${ }^{10}$ Only few clinical studies with the primary objective to verify the efficacy and safety of monotherapy are published. ${ }^{11,12}$ The results from observational registries can provide good information about the duration of therapy. However, these registers are subject to a bias effect 


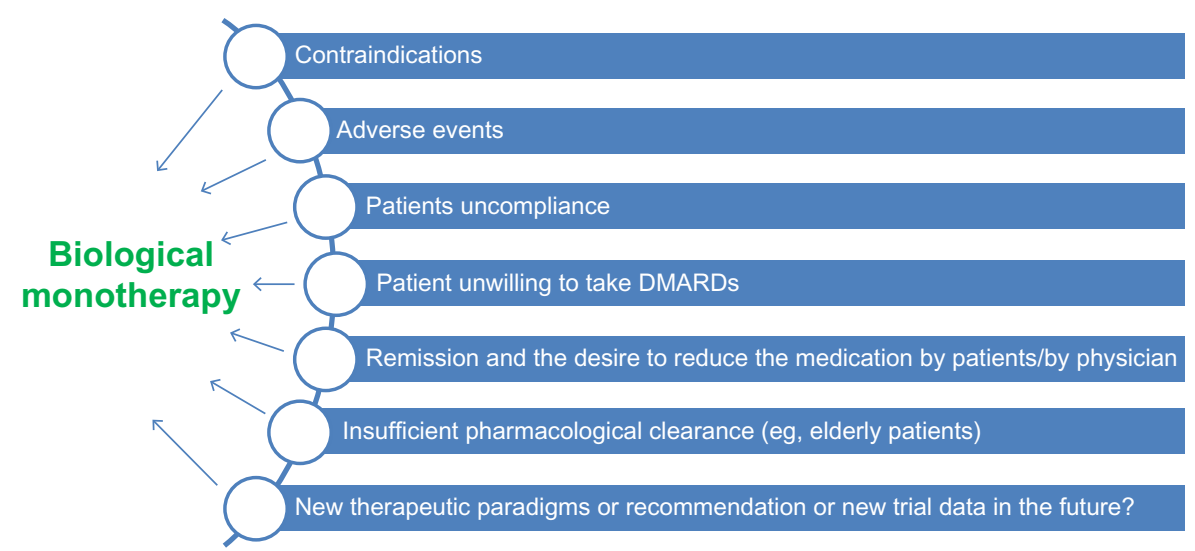

Figure I Some reasons for the decision to perform a monotherapy.

Note: Data from Emery et al. ${ }^{17}$

Abbreviation: DMARDs, disease-modifying antirheumatic drugs.

and are therefore potentially limited in the final statement on monotherapy. ${ }^{10,13}$ The analysis of the study data leads to treatment with tumor necrosis factor (TNF) inhibitors, and so far, results have shown that the concomitant MTX treatment leads to an increased effectiveness and long-term persistence. ${ }^{10,14,15}$

However, future biological monotherapies will gain their clinical value and be supported by further comparative studies. Elderly patients may highlight the monotherapy as a valuable option, especially if the application of the drugs is also suitable or not contraindicated in them. ${ }^{12,16}$

A recent and challenging need is the further optimization of therapy for achieving remission in every stage of the disease. For this review article, PubMed, MEDLINE, EMBASE, and Cochrane Library databases literature and clinical trial register (http://www.clinicaltrial.gov) were searched for clinical studies with the aim of analyzing biological monotherapy in RA. Both authors independently examined each eligible study and extracted data. Trials and research data information only in abstract format were excluded. Due to the objectives of the review, we limited ourselves to prospective, randomized clinical trials, data from registers, summaries of biologic monotherapies, and recommendation. We have tested results of reviews and recommendations.

\section{Use of biologic monotherapy in the treatment of RA}

Approximately $30 \%-33.6 \%$ of RA patients are receiving biologics as monotherapy. These data are supported by various observation registers. ${ }^{18,19}$ Most clinical studies support the higher efficacy of combination therapy of traditional csDMARDs with biological agents, while the same clinical efficacy was seen in the direct comparison of monotherapy with MTX or biologics. Data are available from biological monotherapy studies and from observational registers for abatacept (ABA), ${ }^{20,21}$ adalimumab (ADA), ${ }^{11,22}$ anakinra, ${ }^{23}$ certolizumab (CZP), ${ }^{24}$ etanercept (ETA), ${ }^{25,26}$ golimumab (GOL), ${ }^{27,28}$ infliximab (IFX), ${ }^{29}$ rituximab (RTX), ${ }^{30,31}$ tocilizumab (TCZ), ${ }^{32,33}$ and tofacitinib (TOF). ${ }^{34}$ Table 1 shows the most important data for biologics application.

\section{Effectiveness of biologic monotherapy vs combination therapy with csDMARDs \\ Abatacept}

There are several studies on ABA in monotherapy available. In an early pilot study of ABA, a Phase II study with patients who were treated unsuccessfully with at least one DMARD, ABA monotherapy was compared to placebo ADA..$^{35}$ There was a higher proportion of patients with American College of Rheumatology (ACR) 20 response in the treatment group with the highest ABA dosage of $10 \mathrm{mg} / \mathrm{kg}$ compared to placebo ( $53 \%$ vs $31 \%){ }^{35}$

The ARRIVE trial was a six-month open-label study. One thousand forty-six patients after inadequate response to anti-TNF therapy for 3 months or longer and with disease activity score (DAS) 28 of 5.1 or greater were included in this study. The trial compared a wash-out phase after switching to ABA with patients switching directly. Forty-three of these patients received $\mathrm{ABA}$ as monotherapy; there was no placebo group. ${ }^{36}$ The investigators observed a slightly lower efficacy of ABA in monotherapy: the percentage of patients with a clinically meaningful improvement in DAS 28 was $48.8 \%$ in the monotherapy subgroup compared to $56.1 \%$ of patients receiving combination therapy with MTX. ${ }^{36}$ 
Table I Most important data for biologics use

\begin{tabular}{llll}
\hline Substance & Approval for & Application form & Application interval \\
\hline Abatacept & Plus MTX & iv & Every other 4 weeks \\
Adalimumab & Plus MTX and monotherapy* & sc & Every other 2 weeks \\
Anakinra & Plus MTX** & sc & Daily \\
Certolizumab & Monotherapy & sc & Every other 2 weeks \\
Etanercept & Plus MTX and monotherapy* & sc & Weekly \\
Golimumab & Plus MTX & sc & Every other 4 weeks \\
Infliximab & Plus MTX & iv & 0 week, 2 weeks, 6 weeks, and 8 weeks \\
Rituximab & Plus MTX & iv & TNF inhibition \\
Tocilizumab & Monotherapy & iv & Weeks 0 and 2 \\
CP-690550 tofacitinib & Monotherapy & Oral & Every other 4 weeks
\end{tabular}

Notes: *In cases of contraindications or adverse events, they can be used as monotherapy; **in Europe.

Abbreviations: iv, intravenously; sc, subcutaneously; MTX, methotrexate; TNF, tumor necrosis factor; IL, interleukin; JAK3, Janus kinase inhibitor 3.

The ACCOMPANY trial is an ongoing randomized open-label study comparing $125 \mathrm{mg}$ weekly ABA monotherapy with or without MTX. ${ }^{21}$ ABA is administered subcutaneously. The short-time phase included 100 patients and lasted for 4 months. Patients then entered the ongoing long-term extension phase where MTX could be added at the investigator's discretion. During the short-term phase, mean DAS28 improvement was actually numerically better in the monotherapy group (changes were -1.67 for combination and -1.94 for monotherapy). ${ }^{21}$ To verify the effectiveness and to predict effectiveness factors of ABA in real life, a prospective observational study was performed (the French "Orencia and Rheumatoid Arthritis" [ORA] prospective registry) with 1,003 RA patients. Seven hundred and seventy-three patients had already fulfilled the 6-month follow-up visit. Efficacy was determined by the European League Against Rheumatism (EULAR) response. ${ }^{37}$ In addition, the rheumatological antibodies (rheumatoid factor, anti-cyclic citrullinated peptide antibody [anti-CCP]) of the patients were evaluated. Real-life efficacy of ABA in the registry was similar as that reported in clinical trials. Anti-CCP positivity was associated with a better response to ABA, independently from DAS28. ${ }^{38}$

\section{Adalimumab}

ADA is licensed for monotherapy when administration of MTX is not possible. In a double-blind, Phase III study, 544 patients with previous failure of DMARDs were randomized to receive one of the four different dosages of ADA or placebo. ${ }^{39}$ The investigators demonstrated that all dosages were superior to placebo. In the PREMIER trial, however, where 799 patients with early RA who were MTX naïve received MTX, ADA, or MTX plus ADA for 2 years, there was a twofold higher percentage of patients with combination therapy achieving remission compared to MTX or
ADA alone. When comparing only the two monotherapy groups alone, there was a lower radiographic progression in ADA compared to MTX. ${ }^{22}$

The open-label extension of the PREMIER trial was conducted in the combination of ADA with slightly less MTX as the lack of efficacy was canceled in ADA monotherapy. The prevention of radiological progression is more efficient in patients who were randomized to ADA plus MTX (change in total modified Sharp score $=4.0,8.8$, and 11.0 at year 10 for the initial ADA plus MTX, ADA, and MTX arms, respectively). ${ }^{11}$ The combination therapy appears far more effective than monotherapy in the results. If possible, the combination therapy with MTX over biological monotherapy should be preferred, and the combination therapy should appear for approval.

\section{Anakinra}

In the European monotherapy study, $43 \%$ of patients receiving $150 \mathrm{mg} /$ day antinuclear antibody (ANA) achieved a 20\% response according to the ACR20 criteria, compared to $27 \%$ in the placebo group. ${ }^{40}$ The clinically meaningful improvements in the Health Assessment Questionnaire scores were observed. The mean change in the total modified Sharp score of patients who completed treatment with ANA was significantly less than in the patients who received placebo (2.21 vs 3.81). ${ }^{41,42} \mathrm{~A}$ treatment effect was not observed in the low-dose monotherapy study. ${ }^{23}$

\section{Certolizumab}

CZP is also licensed for monotherapy when administration of MTX is not possible. In the FAST4WARD trial, 220 patients who have failed one or more DMARDs were randomized to receive CZP monotherapy or placebo for 6 months. The proportion of patients who achieved an ACR20 response 
was greater in the monotherapy group than in the placebo group. ${ }^{43}$ The REALISTIC trial was a Phase IIIb study with 1,063 patients who have failed at least one DMARD and were randomized $4: 1$ to receive CZP or placebo in addition to their current therapy. ${ }^{44}$

This included approximately $20 \%$ of patients without concomitant DMARD use. There was a significant improvement in the ACR20 response regardless of concomitant csDMARD use. ${ }^{44}$

\section{Etanercept}

In the ETA trial, 632 patients with early RA were randomized to receive $10 \mathrm{mg}$ or $25 \mathrm{mg}$ of ETA in monotherapy weekly or oral MTX for 12 months. ${ }^{45}$ In the group of patients receiving the higher dose of ETA, there was a more rapid improvement, and higher percentage was having ACR20, 50, and 70 improvement during the first 6 months compared to MTX. After 12 months, there was no statistical difference between the two groups regarding ACR responses. However, the overall increase in bone erosion scores was lower in the ETA group than in the MTX group, both after 6 months and after 12 months. ${ }^{45}$ Patients from TEMPO $(n=682)$ and RADIUS II ( $\mathrm{n}=4341)$ trials who received ETA monotherapy showed similar remission rates in Clinical Disease Activity Index (CDAI) at year 3 (39\% and 35\%, respectively). MTXand ETA-treated patients showed remission rates of $54 \%$ and $36 \%$, respectively. More patients with lower baseline CDAI scores achieved remission than those with higher scores. ${ }^{26}$

In the COMET trial, patients with early RA $(n=542)$ received either ETA plus MTX or MTX alone for 1 year. ${ }^{46}$ After that time, patients with combination therapy were randomized to continue on combination therapy or receive ETA in monotherapy. Patients from the original MTX monotherapy group were randomized to continue MTX monotherapy or to receive additional ETA. Removal of MTX from patients receiving combination therapy resulted in deteriorated clinical and radiographic results compared to patients who continued combination therapy. ${ }^{47}$ There were also several studies with patients who previously had an inadequate response to MTX. In the open-label ADORE trial, ETA added to patients' baseline MTX was compared to switching to ETA monotherapy. Overall, there was a significant clinical improvement from baseline in both groups, and no significant differences between the two groups were observed. ${ }^{48}$ In the JESMR trial, ETA plus MTX was significantly superior to ETA alone regarding both clinical response and radiographic progression. ${ }^{49}$ The CAMEO trial was another study where patients were treated with combination therapy of ETA plus MTX and then randomized to continue combination therapy or switch to ETA monotherapy. Patients in the ETA monotherapy group deteriorated compared to combination therapy. This was especially the case for patients who were not in remission or having low disease activity at the time of randomization. ${ }^{50}$ Data from the Swedish biologics registry showed that patients had better adherence to therapy when they received ETA combined with MTX as opposed to ETA monotherapy. This was also the case for IFX monotherapy. Reasons for withdrawal were both lack of efficacy and the occurrence of AEs. The authors attributed this to the formation of antidrug antibodies (ADrAb) ${ }^{51}$ In the ETA treatment, the combination therapy with MTX in the results was shown to be far more effective than monotherapy. Therefore, the combination treatment with MTX should be preferred here too, if possible, and corresponds to the primary ETA approval.

\section{Golimumab}

In the GO-BEFORE trial, 637 MTX-naïve patients were randomized to receive GOL plus MTX or GOL or MTX alone. According to the intention-to-treat population, combination therapy was not superior to MTX. There was a significant advantage of GOL and MTX compared to either substance alone than three untreated patients in the post hoc analysis were excluded. ${ }^{15}$ There were no significant differences between GOL or MTX monotherapy. In the GO-FORWARD study, patients with insufficient response to MTX were randomized to receive GOL plus MTX or either drug alone. ${ }^{27}$ There was a better clinical response in the combination group compared to GOL or MTX alone. ${ }^{16}$ Of note, GOL monotherapy was significantly superior to MTX monotherapy regarding ACR20 response.

\section{Infliximab}

There are few studies that demonstrate the efficacy of IFX monotherapy, but there are no trials comparing IFX monotherapy to MTX. ${ }^{52}$ One reason for this may be the fact that it was recognized relatively quickly that infusion-related side effects in combination with MTX could be reduced. Nevertheless, an evaluation of an observation register shows that in the case of MTX contraindications, IFX monotherapy provides similar efficacy as ETA. ${ }^{53}$ In a retrospective cohort study from the USA using Medicare data with over 10,500 patients using a TNF inhibitor in monotherapy, patients with IFX alone were 1.8 times more likely to discontinue medication compared to patients using combination therapy 
with MTX. Patients with other TNF inhibitors were 1.4 times more likely to discontinue therapy when using monotherapy. The authors postulated that this was mostly due to the immunogenic potential of IFX. ${ }^{16}$

\section{Rituximab}

In an open-label Phase II study, patients with inadequate response to MTX were randomized to receive RTX plus MTX or cyclophosphamide or MTX or RTX in monotherapy. RTX plus MTX was superior to RTX or MTX alone according to, for example, ACR50 response. RTX monotherapy was also superior to MTX monotherapy, and the difference in response rates between RTX alone and MTX alone was more pronounced than between combination therapy and RTX alone. ${ }^{54}$ In a small open-label study, 40 patients were randomized to receive a single infusion of RTX plus MTX or RTX alone. Again, there were better ACR response rates in the combination group. ${ }^{55}$ There was also a trend suggesting earlier repopulation of B cells in the monotherapy group which could indicate shorter duration of clinical response.

\section{Tocilizumab}

In an early Japanese Phase I/II study, 162 patients with insufficient response to csDMARDs were randomized to receive TCZ or placebo. There was a significant clinical benefit of both doses of TCZ over placebo. ${ }^{56} \mathrm{TCZ}$ monotherapy was also significantly superior to MTX monotherapy in patients who were refractory to csDMARDs. ${ }^{56,57}$ In the SAMURAI study, patients treated with TCZ had reduced radiographic progression and a better clinical response compared to MTX. Interestingly, the dosage of MTX was rather low with only $8 \mathrm{mg}$ per week. Typically, in other studies, the dosage would be between $15 \mathrm{mg}$ and $25 \mathrm{mg}$ per week. ${ }^{57}$ In the AMBITION trial, 673 MTX-naïve patients were randomized to receive TCZ monotherapy or MTX monotherapy (starting at $7.5 \mathrm{mg}$ per week and titrating up to $20 \mathrm{mg}$ per week within the first 8 weeks). After 24 weeks, there was a significantly higher percentage of patients with an ACR response or DAS28 low disease activity in the TCZ group compared to MTX.$^{58}$ In the ACT-RAY trial, patients with inadequate response to MTX were randomized to receive additional TCZ or switch to TCZ monotherapy. ${ }^{25}$ No clinically relevant benefit of the combination therapy was observed compared to TCZ monotherapy. ${ }^{59}$ In the ADACTA trial, TCZ monotherapy was compared to ADA monotherapy. TCZ was significantly superior to ADA in all endpoints. This trial will be discussed in greater detail below. $^{32}$

\section{Tofacitinib}

TOF is not a biologic but a Janus kinase inhibitor belonging to the novel group of oral small molecules for the treatment of RA. TOF monotherapy has been compared to placebo in several studies. ${ }^{60}$ In the ORAL Solo trial, 611 patients with inadequate response to bDMARDs or csDMARDs were randomized to receive one of the three different dosing regimens or placebo. TOF was significantly superior to placebo. ${ }^{61}$ These findings were confirmed in the ORAL Start trial with 958 MTX-naïve patients. To date, there are no completed studies available comparing TOF monotherapy to TOF plus MTX. ${ }^{34}$ However, the ORAL STRATEGY trial is currently recruiting patients with inadequate MTX response to compare TOF alone with TOF plus MTX and ADA plus MTX (NCT02187055).

\section{Safety of biologic monotherapy vs combination therapy with csDMARDs}

\section{General safety considerations}

According to the available data from the large randomized controlled clinical trials, there is no added safety risk when combining biologics with csDMARDs. This was confirmed by a recent meta-analysis. ${ }^{62}$ Vice versa, biologics in monotherapy do not have a lower safety risk compared to combination therapy. Typical safety concerns associated with bDMARD and csDMARD therapy are infections including severe respiratory tract infections, reactivation of tuberculosis and hepatitis B, nonmelanoma skin malignancies, injection-site reactions, and zytopenia. ${ }^{63}$ For example, for $\mathrm{ABA}$, there was a comparable rate of AEs and severe AEs (SAEs) in the ARRIVE study both in the monotherapy and in the combination therapy groups. ${ }^{36}$ In the ACCOMANY trial, there was a slightly higher rate of SAEs in the monotherapy group and a slightly higher rate of AEs in the combination therapy group. ${ }^{21}$ For ADA, there was a comparable rate of AEs and SAEs in the PREMIER trial in all three groups (MTX, ADA, or MTX plus ADA), but serious infections were more frequent in the combination therapy group $(2.9 \%)$ compared to ADA alone $(0.7 \% ; P<0.05) .{ }^{22}$ In the ERA trial, there was a lower overall incidence of AEs and fewer infections in the ETA monotherapy group than in the MTX monotherapy group. ${ }^{45}$ In the TEMPO trial, there were also a similar number of AEs and infections in patients receiving ETA or MTX in monotherapy or the combination of both. ${ }^{64,65}$ Also, in the COMET trial, there was no additional 
safety risk in patients receiving combination therapy. ${ }^{46,47}$ For GOL, there was a slightly higher overall incidence of AEs in the two combination groups compared to either substance in monotherapy in the GO-BEFORE trial. ${ }^{66}$ Similar rates of AEs were observed in both RTX monotherapy and combination therapy trials..$^{54,55}$ TOF has a safety profile that is similar to bDMARDs. In addition, elevated low-density and high-density lipoprotein cholesterol levels and reduced neutrophil counts can occur. There has been a slightly higher rate of overall AEs in the TOF plus MTX group compared to MTX alone. ${ }^{67,68}$

\section{Antidrug antibodies}

The development of ADrAb has been associated with bDMARD as they present an immunogenic target for the immune system. The formation of ADrAb has been observed for most biologics. ${ }^{69}$ Low titers are thought not to influence the efficacy of the drug, whereas high titers may impair the efficacy by neutralizing the drug. Concomitant administration of other immunosuppressive drugs such as MTX has been shown to reduce the incidence of ADrAb. ${ }^{69}$ In the ACCOMPANY trial for ABA, transient immunogenicity with detection of $A D r A b$ was seen in approximately $4 \%$ of patients regardless of concomitant MTX use. After 4 months, however, anti-ABA antibodies were detected in none of the patients. ${ }^{21}$ For ADA, MTX has been shown to reduce immunogenicity in a dose-dependent manner. ${ }^{70}$ For CZP, the formation of ADrAb has been found in approximately $12 \%$ of patients, with unknown clinical significance. ${ }^{71}$ Forty-four percent of RA patients were positive for anti-IFN after 6 months of treatment. ${ }^{72,73}$ Antibodies against TCZ have been found in only a small number of patients, and treatment efficacy was maintained even in the presence of those antibodies. ${ }^{74}$ The formation of ADrAb was not affected by concomitant use of MTX in the ACTRAY trial. ${ }^{59}$ The impact of baseline ANA status and use of MTX play a major role in the development of IFX-related infusion reactions in patients. The risk of an allergic infusion reaction is particularly high if the ANA status in the patient is positive at baseline and if IFX is administered as monotherapy. ${ }^{75}$

\section{Comparative effectiveness of biologic monotherapies: the ADACTA trial}

The next step is the conversion to other csDMARDs if the patient cannot tolerate MTX. ${ }^{7}$ However, if signs of a high disease activity and if already radiologically demonstrable erosions are present, the patient can be directly switched to monotherapy with a biologic. According to the data from ADACTA trial, TCZ appears to be suitable for first-line biologic therapy. In a head-to-head comparison, it was found to be superior to ADA monotherapy. ${ }^{32}$

Patients from ADACTA trial were randomly assigned to receive $8 \mathrm{mg}$ TCZ per kilogram bodyweight intravenously every 4 weeks plus placebo subcutaneously every 2 weeks or $40 \mathrm{mg}$ ADA subcutaneously every 2 weeks plus placebo intravenously every 4 weeks for 24 weeks. Three hundred and twenty-six patients enrolled in this trial. The mean change from baseline in DAS28 was significantly greater at week 24 in the TCZ group than in the ADA group (difference -1.5, $95 \%$ confidence interval -1.8 to $-1.1 ; P<0.0001){ }^{32}$ The recommendations for TCZ monotherapy are supported by the results of the ACT-RAY study. They showed that TCZ as monotherapy and in combination with MTX shows a similar rate of DAS28 remission at week 24 (34.8\% vs 40.4\%; $P=0.21$ ). In addition, the patients showed a similar reduction in the number of swollen joints and tenderness of joints at weeks 24 and $52 .{ }^{59}$

The results of the safety analysis in the ADACTA trial showed only marginal differences. In the ADA group (16 [10\%] of 162), there appeared slightly less serious adverse effects than in the TCZ group (19 [12\%] of 162). The TCZ group had more patients with increased low-density lipoprotein cholesterol, increased alanine aminotransferase concentrations, and reduced platelet and neutrophil counts than the ADA group..$^{32}$ But what we do not know is how the monotherapy with TCZ could be compared to the combination of MTX and ADA. The ADACTA trial does not provide a comparison with standard therapy. The results therefore provide no justification for an increased indication of monotherapy.

\section{Conclusion and future research perspectives}

In general, biologics enrich and change the RA therapy. This applies to all biologics. TCZ shows good efficacy and tolerability. Of course, patients treated with TCZ do not respond or show any side effects as with other biologics. TCZ should also be used in monotherapy if the treatment is established for it. In addition, there is the possibility that an accompanying csDMARD subsequently could be discontinued if a good response to therapy reduces the burden on the patient. This procedure must be documented in future with study data, as well as comparative studies with other biologics as monotherapy. As the first choice in the treatment of RA patients csDMARDs should be preferred, 
because a sufficiency treatment is possible for most patents and treatment with biologics is very costly. Also, the previous long-term data show that especially, combination treatments (csDMARD with bDMARD) are often more effective than monotherapy alone.

\section{Disclosure}

The authors report no conflicts of interest in this work.

\section{References}

1. Silman AJ, Hochberg MC, editors. Epidemiology of the Rheumatic Diseases: Rheumatoid Arthritis. New York: Oxford University Press; 2001.

2. Brooks PM. The burden of musculoskeletal disease - a global perspective. Clin Rheumatol. 2006;25(6):778-781.

3. Scott DL, Wolfe F, Huizinga TWJ. Rheumatoid arthritis. Lancet. 2010;376(9746):1094-1108.

4. McInnes IB, Schett G. The pathogenesis of rheumatoid arthritis. NEngl J Med. 2011;365(23):2205-2219.

5. Smolen JS, Landewé R, Breedveld FC, et al. EULAR recommendations for the management of rheumatoid arthritis with synthetic and biological disease-modifying antirheumatic drugs. Ann Rheum Dis. 2010;69(6):964-975.

6. Smolen JS, Landewé R, Breedveld FC, et al. EULAR recommendations for the management of rheumatoid arthritis with synthetic and biological disease-modifying antirheumatic drugs: 2013 update. Ann Rheum Dis. 2014;73(3):492-509.

7. Smolen JS, Aletaha D, Bijlsma JW, et al; T2T Expert Committee. Treating rheumatoid arthritis to target: recommendations of an international task force. Ann Rheum Dis. 2010;69(4):631-637.

8. Grigor C, Capell H, Stirling A, et al. Effect of a treatment strategy of tight control for rheumatoid arthritis (the TICORA study): a single-blind randomised controlled trial. Lancet. 2004;364(9430):263-269.

9. Choquette D, Thomas O, Arundine M. Lower than expected levels of DMARD acquisition immediately pre and post biologic initiation in rheumatoid arthritis patients. Arthritis Rheum. 2012;64(Suppl 10): 1841.

10. Ruderman EM. The role of concomitant methotrexate in biologic therapy for rheumatoid arthritis. Bull Hosp Jt Dis. 2013;2013(71 Suppl 1): S29-S32.

11. Keystone EC, Breedveld FC, van der Heijde D, et al. Longterm effect of delaying combination therapy with tumor necrosis factor inhibitor in patients with aggressive early rheumatoid arthritis: 10-year efficacy and safety of adalimumab from the randomized controlled PREMIER trial with open-label extension. J Rheumatol. 2014;41(1):5-14.

12. Lethaby A, Lopez-Olivo MA, Maxwell L, Burls A, Tugwell P, Wells GA. Etanercept for the treatment of rheumatoid arthritis. Cochrane Database Syst Rev. 2013;5:CD004525.

13. Jansen JP, Buckley F, Dejonckheere F, Ogale S. Comparative efficacy of biologics as monotherapy and in combination with methotrexate on patient reported outcomes (PROs) in rheumatoid arthritis patients with an inadequate response to conventional DMARDs - a systematic review and network meta-analysis. Health Qual Life Outcomes. 2014;12:102.

14. Castrejón I, Gibson KA, Pincus T. Efficacy and safety of methotrexate in combination with other non-biologic disease-modifying antirheumatic drugs (DMARDs) in treatment of rheumatoid arthritis. Bull Hosp Jt Dis. 2013;2013(71 Suppl 1):S20-S28.

15. Pincus T, Gibson KA, Castrejón I. Update on methotrexate as the anchor drug for rheumatoid arthritis. Bull Hosp Jt Dis. 2013;2013(71 Suppl 1): S9-S19.

16. Zhang J, Xie F, Delzell E, et al. Impact of biologics with and without concomitant MTX and at reduced doses in older rheumatoid arthritis patients. Arthritis Care Res (Hoboken). Epub 2014 Nov 4.
17. Emery P, Sebba A, Huizinga TWJ. Biologic and oral disease-modifying antirheumatic drug monotherapy in rheumatoid arthritis. Ann Rheum Dis. 2013;72(12):1897-1904.

18. Yazici Y, Shi N, John A. Utilization of biologic agents in rheumatoid arthritis in the United States: analysis of prescribing patterns in 16,752 newly diagnosed patients and patients new to biologic therapy. Bull NYU Hosp Jt Dis. 2008;66(2):77-85.

19. Soliman MM, Ashcroft DM, Watson KD, Lunt M, Symmons DPM, Hyrich KL. Impact of concomitant use of DMARDs on the persistence with anti-TNF therapies in patients with rheumatoid arthritis: results from the British Society for Rheumatology Biologics Register. Ann Rheum Dis. 2011;70(4):583-589.

20. Vicente Rabaneda EF, Herrero-Beaumont G, Castañeda S. Update on the use of abatacept for the treatment of rheumatoid arthritis. Expert Rev Clin Immunol. 2013;9(7):599-621.

21. Nash P, Nayiager S, Genovese MC, et al. Immunogenicity, safety, and efficacy of abatacept administered subcutaneously with or without background methotrexate in patients with rheumatoid arthritis: results from a phase III, international, multicenter, parallel-arm, open-label study. Arthritis Care Res (Hoboken). 2013;65(5):718-728.

22. Breedveld FC, Weisman MH, Kavanaugh AF, et al. The PREMIER study: a multicenter, randomized, double-blind clinical trial of combination therapy with adalimumab plus methotrexate versus methotrexate alone or adalimumab alone in patients with early, aggressive rheumatoid arthritis who had not had previous methotrexate treatment. Arthritis Rheum. 2006;54(1):26-37.

23. Bresnihan B. Anakinra as a new therapeutic option in rheumatoid arthritis: clinical results and perspectives. Clin Exp Rheumatol. 2002;20(5 Suppl 27):S32-S34.

24. Fechtenbaum M, Md Yusof MY, Emery P. Certolizumab pegol in rheumatoid arthritis: current update. Expert Opin Biol Ther. 2014;14(6): $841-850$.

25. Curtis JR, Yang S, Chen L, et al. Predicting low disease activity and remission using early treatment response to antitumour necrosis factor therapy in patients with rheumatoid arthritis: exploratory analyses from the TEMPO trial. Ann Rheum Dis. 2012;71(2):206-212.

26. Cannon GW, Wang BC, Park GS, Koenig A, Collier DH, Keystone EC. Remission in rheumatoid arthritis patients treated with etanercept monotherapy: clinical practice and clinical trial experience. Clin Exp Rheumatol. 2013;31(6):919-925.

27. Keystone EC, Genovese MC, Hall S, et al. Golimumab in patients with active rheumatoid arthritis despite methotrexate therapy: results through 2 years of the GO-FORWARD study extension. J Rheumatol. 2013;40(7):1097-1103.

28. Genovese MC, Han C, Keystone EC, et al. Effect of golimumab on patient-reported outcomes in rheumatoid arthritis: results from the GO-FORWARD study. J Rheumatol. 2012;39(6):1185-1191.

29. Nam JL, Ramiro S, Gaujoux-Viala C, et al. Efficacy of biological diseasemodifying antirheumatic drugs: a systematic literature review informing the 2013 update of the EULAR recommendations for the management of rheumatoid arthritis. Ann Rheum Dis. 2014;73(3):516-528.

30. Richter A, Strangfeld A, Herzer P, et al. Sustainability of rituximab therapy in different treatment strategies: results of a 3-year followup of a german biologics register. Arthritis Care Res (Hoboken). 2014;66(11): $1627-1633$.

31. Wendler J, Burmester GR, Sörensen H, et al. Rituximab in patients with rheumatoid arthritis in routine practice (GERINIS): six-year results from a prospective, multicentre, non-interventional study in 2,484 patients. Arthritis Res Ther. 2014;16(2):R80.

32. Gabay C, Emery P, van Vollenhoven R, et al; ADACTA Study Investigators. Tocilizumab monotherapy versus adalimumab monotherapy for treatment of rheumatoid arthritis (ADACTA): a randomised, doubleblind, controlled phase 4 trial. Lancet. 2013;381(9877):1541-1550.

33. Nakashima Y, Kondo M, Miyahara H, Iwamoto Y. Drug delivery options to increase patient adherence and satisfaction in the management of rheumatoid arthritis - focus on subcutaneous tocilizumab. Drug Des Devel Ther. 2014;8:913-919. 
34. Lee EB, Fleischmann R, Hall S, et al; ORAL Start Investigators. Tofacitinib versus methotrexate in rheumatoid arthritis. N Engl J Med. 2014;370(25):2377-2386.

35. Moreland LW, Alten R, Van den Bosch F, et al. Costimulatory blockade in patients with rheumatoid arthritis: a pilot, dose-finding, double-blind, placebo-controlled clinical trial evaluating CTLA-4Ig and LEA29Y eighty-five days after the first infusion. Arthritis Rheum. 2002;46(6): $1470-1479$

36. Schiff M, Pritchard C, Huffstutter JE, et al. The 6-month safety and efficacy of abatacept in patients with rheumatoid arthritis who underwent a washout after anti-tumour necrosis factor therapy or were directly switched to abatacept: the ARRIVE trial. Ann Rheum Dis. 2009;68(11): $1708-1714$

37. van Riel PL, van Gestel AM, Scott DL. EULAR handbook of clinical assessments in rheumatoid arthritis. Alphen Aan Den Rijn. The Netherlands: Van Zuiden Communications, BV; 2000:1-54.

38. Gottenberg JE, Ravaud P, Cantagrel A, et al. Positivity for anti-cyclic citrullinated peptide is associated with a better response to abatacept: data from the 'Orencia and Rheumatoid Arthritis' registry. Ann Rheum Dis. 2012;71(11):1815-1819.

39. van de Putte LB, Atkins C, Malaise M, et al. Efficacy and safety of adalimumab as monotherapy in patients with rheumatoid arthritis for whom previous disease modifying antirheumatic drug treatment has failed. Ann Rheum Dis. 2004;63(5):508-516.

40. Nuki G, Bresnihan B, Bear MB, McCabe D. Long-term safety and maintenance of clinical improvement following treatment with anakinra (recombinant human interleukin-1 receptor antagonist) in patients with rheumatoid arthritis: extension phase of a randomized, double-blind, placebo-controlled trial. Arthritis Rheum. 2002;46(11): 2838-2846.

41. Bresnihan B, Alvaro-Gracia JM, Cobby M, et al. Treatment of rheumatoid arthritis with recombinant human interleukin-1 receptor antagonist. Arthritis Rheum. 1998;41(12):2196-2204.

42. Bresnihan B, Newmark R, Robbins S, Genant HK. Effects of anakinra monotherapy on joint damage in patients with rheumatoid arthritis. Extension of a 24-week randomized, placebo-controlled trial. J Rheumatol. 2004;31(6):1103-1111.

43. Fleischmann R, Vencovsky J, van Vollenhoven RF, et al. Efficacy and safety of certolizumab pegol monotherapy every 4 weeks in patients with rheumatoid arthritis failing previous disease-modifying antirheumatic therapy: the FAST4WARD study. Ann Rheum Dis. 2009;68(6): $805-811$.

44. Weinblatt ME, Fleischmann R, Huizinga TW, et al. Efficacy and safety of certolizumab pegol in a broad population of patients with active rheumatoid arthritis: results from the REALISTIC phase IIIb study. Rheumatology (Oxford, England). 2012;51(12):2204-2214.

45. Bathon JM, Martin RW, Fleischmann RM, et al. A comparison of etanercept and methotrexate in patients with early rheumatoid arthritis. $N$ Engl J Med. 2000;343(22):1586-1593.

46. Emery P, Breedveld FC, Hall S, et al. Comparison of methotrexate monotherapy with a combination of methotrexate and etanercept in active, early, moderate to severe rheumatoid arthritis (COMET): a randomised, doubleblind, parallel treatment trial. Lancet. 2008;372(9636): 375-382.

47. Emery P, Breedveld F, van der Heijde D, et al; Combination of Methotrexate and Etanercept in Early Rheumatoid Arthritis Trial Group. Two-year clinical and radiographic results with combination etanercept-methotrexate therapy versus monotherapy in early rheumatoid arthritis: a two-year, double-blind, randomized study. Arthritis Rheum. 2010;62(3):674-682.

48. van Riel PL, Taggart AJ, Sany J, et al; Add Enbrel or Replace Methotrexate Study Investigators. Efficacy and safety of combination etanercept and methotrexate versus etanercept alone in patients with rheumatoid arthritis with an inadequate response to methotrexate: the ADORE study. Ann Rheum Dis. 2006;65(11):1478-1483.

49. Kameda H, Kanbe K, Sato E, et al. Continuation of methotrexate resulted in better clinical and radiographic outcomes than discontinuation upon starting etanercept in patients with rheumatoid arthritis: 52-week results from the JESMR study. J Rheumatol. 2011;38(8): 1585-1592.
50. Pope JE, Haraoui B, Thorne JC, Vieira A, Poulin-Costello M, Keystone EC. The Canadian methotrexate and etanercept outcome study: a randomised trial of discontinuing versus continuing methotrexate after 6 months of etanercept and methotrexate therapy in rheumatoid arthritis. Ann Rheum Dis. 2014;73(12):2144-2151.

51. Kristensen LE, Saxne T, Nilsson J, Geborek P. Impact of concomitant DMARD therapy on adherence to treatment with etanercept and infliximab in rheumatoid arthritis. Results from a six-year observational study in southern Sweden. Arthritis Res Ther. 2006;8(6):R174.

52. Maini RN, Breedveld FC, Kalden JR, et al. Therapeutic efficacy of multiple intravenous infusions of anti-tumor necrosis factor alpha monoclonal antibody combined with low-dose weekly methotrexate in rheumatoid arthritis. Arthritis Rheum. 1998;41(9):1552-1563.

53. Hyrich KL, Symmons DPM, Watson KD, Silman AJ. Comparison of the response to infliximab or etanercept monotherapy with the response to cotherapy with methotrexate or another disease-modifying antirheumatic drug in patients with rheumatoid arthritis: results from the British Society for Rheumatology Biologics Register. Arthritis Rheum. 2006;54(6):1786-1794.

54. Edwards JCW, Szczepanski L, Szechinski J, et al. Efficacy of B-celltargeted therapy with rituximab in patients with rheumatoid arthritis. N Engl J Med. 2004;350(25):2572-2581.

55. Owczarczyk K, Hellmann M, Fliedner G, et al. Clinical outcome and $\mathrm{B}$ cell depletion in patients with rheumatoid arthritis receiving rituximab monotherapy in comparison with patients receiving concomitant methotrexate. Ann Rheum Dis. 2008;67(11):1648-1649.

56. Nishimoto N, Yoshizaki K, Miyasaka N, et al. Treatment of rheumatoid arthritis with humanized anti-interleukin- 6 receptor antibody: a multicenter, double-blind, placebo-controlled trial. Arthritis Rheum. 2004;50(6):1761-1769.

57. Nishimoto N, Hashimoto J, Miyasaka N, et al. Study of active controlled monotherapy used for rheumatoid arthritis, an IL-6 inhibitor (SAMURAI): evidence of clinical and radiographic benefit from an $\mathrm{x}$ ray reader-blinded randomised controlled trial of tocilizumab. Ann Rheum Dis. 2007;66(9):1162-1167.

58. Jones G, Sebba A, Gu J, et al. Comparison of tocilizumab monotherapy versus methotrexate monotherapy in patients with moderate to severe rheumatoid arthritis: the AMBITION study. Ann Rheum Dis. 2010; 69(1):88-96.

59. Dougados M, Kissel K, Conaghan PG, et al. Clinical, radiographic and immunogenic effects after 1 year of tocilizumab-based treatment strategies in rheumatoid arthritis: the ACT-RAY study. Ann Rheum Dis. 2014;73(5):803-809.

60. Lundquist LM, Cole SW, Sikes ML. Efficacy and safety of tofacitinib for treatment of rheumatoid arthritis. World J Orthop. 2014;5(4):504-511.

61. Fleischmann R, Kremer J, Cush J, et al; ORAL Solo Investigators. Placebo-controlled trial of tofacitinib monotherapy in rheumatoid arthritis. N Engl J Med. 2012;367(6):495-507.

62. Aaltonen KJ, Virkki LM, Malmivaara A, Konttinen YT, Nordström DC, Blom M. Systematic review and meta-analysis of the efficacy and safety of existing TNF blocking agents in treatment of rheumatoid arthritis. PLoS One. 2012;7(1):e30275.

63. Ramiro S, Gaujoux-Viala C, Nam JL, et al. Safety of synthetic and biological DMARDs: a systematic literature review informing the 2013 update of the EULAR recommendations for management of rheumatoid arthritis. Ann Rheum Dis. 2014;73(3):529-535.

64. Klareskog L, van der Heijde D, de Jager JP, et al; TEMPO (Trial of Etanercept and Methotrexate with Radiographic Patient Outcomes) Study Investigators. Therapeutic effect of the combination of etanercept and methotrexate compared with each treatment alone in patients with rheumatoid arthritis: double-blind randomised controlled trial. Lancet. 2004;363(9410):675-681

65. van der Heijde D, Klareskog L, Rodriguez-Valverde V, et al; TEMPO Study Investigators. Comparison of etanercept and methotrexate, alone and combined, in the treatment of rheumatoid arthritis: two-year clinical and radiographic results from the TEMPO study, a double-blind, randomized trial. Arthritis Rheum. 2006;54(4):1063-1074. 
66. Emery P, Fleischmann RM, Moreland LW, et al. Golimumab, a human anti-tumor necrosis factor alpha monoclonal antibody, injected subcutaneously every four weeks in methotrexate-naive patients with active rheumatoid arthritis: twenty-four-week results of a phase III, multicenter, randomized, double-blind, placebo-controlled study of golimumab before methotrexate as first-line therapy for early-onset rheumatoid arthritis. Arthritis Rheum. 2009;60(8): 2272-2283.

67. van Vollenhoven RF, Fleischmann R, Cohen S, et al; ORAL Standard Investigators. Tofacitinib or adalimumab versus placebo in rheumatoid arthritis. N Engl J Med. 2012;367(6):508-519.

68. Burmester GR, Blanco R, Charles-Schoeman C, et al; ORAL Step investigators. Tofacitinib (CP-690,550) in combination with methotrexate in patients with active rheumatoid arthritis with an inadequate response to tumour necrosis factor inhibitors: a randomised phase 3 trial. Lancet. 2013;381(9865):451-460.

69. van Schouwenburg PA, Rispens T, Wolbink GJ. Immunogenicity of antiTNF biologic therapies for rheumatoid arthritis. Nat Rev Rheumatol. 2013;9(3):164-172.
70. Krieckaert CL, Nurmohamed MT, Wolbink GJ. Methotrexate reduces immunogenicity in adalimumab treated rheumatoid arthritis patients in a dose dependent manner. Ann Rheum Dis. 2012;71(11):1914-1915.

71. Atzeni F, Talotta R, Salaffi F, et al. Immunogenicity and autoimmunity during anti-TNF therapy. Autoimmun Rev. 2013;12(7):703-708.

72. Bendtzen K, Geborek P, Svenson M, Larsson L, Kapetanovic MC, Saxne T. Individualized monitoring of drug bioavailability and immunogenicity in rheumatoid arthritis patients treated with the tumor necrosis factor alpha inhibitor infliximab. Arthritis Rheum. 2006;54(12): 3782-3789.

73. Aarden L, Ruuls SR, Wolbink G. Immunogenicity of anti-tumor necrosis factor antibodies-toward improved methods of anti-antibody measurement. Curr Opin Immunol. 2008;20(4):431-435.

74. Jones G, Ding C. Tocilizumab: a review of its safety and efficacy in rheumatoid arthritis. Clin Med Insights Arthritis Musculoskelet Disord. 2010;3:81-89.

75. Kapetanovic MC, Larsson L, Truedsson L, Sturfelt G, Saxne T, Geborek P. Predictors of infusion reactions during infliximab treatment in patients with arthritis. Arthritis Res Ther. 2006;8(4):R131.
Biologics: Targets \& Therapy

\section{Publish your work in this journal}

Biologics: Targets \& Therapy is an international, peer-reviewed journal focusing on the patho-physiological rationale for and clinical application of Biologic agents in the management of autoimmune diseases, cancers or other pathologies where a molecular target can be identified. This journal is indexed on PubMed Central, CAS, EMBase, Scopus

Submit your manuscript here: http://www.dovepress.com/biologics-targets--therapy-journal

\section{Dovepress}

and the Elsevier Bibliographic databases. The manuscript management system is completely online and includes a very quick and fair peerreview system, which is all easy to use. Visit http://www.dovepress. com/testimonials.php to read real quotes from published authors. 